\title{
Biopolímero desenvolvido a partir da farinha de arroz e sua aplicação como revestimento em frutos
}

\section{Biopolymer developed from rice flour and its application as a coating on fruits}

\author{
Ariane Oliveira Rodrigues ${ }^{1}$, Eyshila Cristina Bitencourt Lucio ${ }^{1}$, Letícia do Carmo Melo ${ }^{1, *}$, Magali Canhamero ${ }^{1}$, Fátima Chagas Silva ${ }^{1}$
}

\section{ABSTRACT}

The use of biopolymers as a post-harvest protective coating of fruits and vegetables stands out for its conservation capacity, providing food with a longer shelf life. In order to protect the external surface of fruits and vegetables, a filmogenic coating of starch was developed from rice flour in order to reduce respiration and the influence of abiotic factors on the fruits. In this context, fruits like tomato (Lycopersicon esculentum) and banana (Musa spp.) were coated with a filmogenic starch solution, containing glycerol and citric acid, and kept at room temperature for 16 days. During this period, the effects of the coating were evaluated through the loss of mass, total titratable acidity, maturation stage, organoleptic properties, and the melting point of the biopolymer. Considering the results obtained by the use of the rice flour starch coating, the reduction in the mass loss and maturation of the fruits and a fungicidal action was clearly observed.

Keywords: Coatings, Biopolymer, Rice flour starch.

\section{RESUMO}

O emprego de biopolímeros como revestimento protetor de frutas e legumes pós-colheita destaca-se pela sua capacidade de conservação, proporcionando aos alimentos maior vida útil. Com o intuito de proteger a superfície externa de frutas e legumes, foi desenvolvido um revestimento filmogênico de amido, a partir da farinha de arroz com a finalidade de reduzir a respiração e a influência de fatores abióticos nesses alimentos. Nesse contexto, frutos, como tomate (Lycopersicon esculentum) e banana (Musa spp.), higienizados foram revestidos com uma solução filmogênica de amido, contendo glicerol e ácido cítrico e, em seguida, expostos à temperatura ambiente por 16 dias. No decorrer desse período, foram avaliados os efeitos do revestimento por meio de análises de perda de massa, acidez titulável total, estágio de maturação, propriedades organolépticas e ponto de fusão do biopolímero. Considerando os resultados obtidos, verificou-se que a utilização do revestimento à base de farinha de arroz reduziu de forma perceptível a perda de massa e a maturação nos frutos e também apresentou ação fungicida.

Palavras-chave: Revestimentos, Biopolímero, Amido da farinha de arroz. 


\section{INTRODUÇÃO}

Estima-se que entre 25 e $35 \%$ das frutas e hortaliças produzidas no mundo são perdidas ou desperdiçadas, e dessa porcentagem cerca de $40 \%$ das perdas se encontram nos estágios de póscolheita, transporte, armazenamento e processamento. Essa problemática apresenta impacto significativo na segurança alimentar de milhões de pessoas ao redor do globo ${ }^{1}$.

As perdas e o desperdício de alimentos ocorrem ao longo de toda a cadeia de valor agrícola e em todas as fases da produção até chegar à mesa do consumidor. Essas desvantagens são provenientes de tecnologias de colheita e pós-colheita insuficientes ou obsoletas; armazenamentos precários, pois muitas vezes o transporte, o processamento e as instalações de refrigeração são inadequados; e infraestrutura e sistemas ineficazes de embalagem e comercialização². Esses fatores reduzem a disponibilidade de alimentos, geram menores recursos para os produtores e aumentam os preços para os consumidores. Além disso, têm efeito negativo no meio ambiente devido à utilização não sustentável dos recursos naturais.

Com o intuito de prolongar a durabilidade de frutas e hortaliças durante os processos de produção e ainda evitar o desperdício de alimentos que ocorre em domicílios, foi avaliada a viabilidade da aplicação de materiais biopolímericos sobre a superfície externa de determinados alimentos naturais, os quais têm a função de protegê-los das intempéries. A farinha de arroz mostra-se favorável como matéria-prima para a produção em larga escala desses biopolímeros, pois é obtida pela moagem dos grãos quebrados, um subproduto do beneficiamento do arroz que possui menor valor e interesse comercial, ou seja, não afeta de modo direto a produção de alimentos, já que não ocorre a retirada de parte da produção ${ }^{3}$.

Assim, o objetivo deste trabalho foi avaliar a eficácia de revestimento à base de amido de farinha de arroz na conservação de tomates do tipo italiano (Lycopersicon esculentum) e bananas tipo nanica (Musa spp.) quando expostos ao meio ambiente através de métodos físico-químicos específicos, tais como acidez total titulável; firmeza da polpa; perda de massa; avaliações organolépticas, como cor e textura da casca; e odores indicadores de senescência ou apodrecimento, devido à infestação por microrganismos. Procurou-se desenvolver um biopolímero passível de ser utilizado como protetor em frutos, mas sem interferir em suas características fundamentais $(\mathrm{pH}$, textura e sabor, entre outras), e industrialmente viável e eficaz.

\section{MATERIAIS E MÉTODOS Materiais e equipamentos}

A farinha de arroz $(1 \mathrm{~kg})$ e os frutos foram adquiridos em comércio comum, observando-se o estado de conservação, presença de microrganismos, partes amassadas, coloração da parte externa, entre outros fatores.

Para a produção do biopolímero e seus ensaios posteriores, fez-se o uso de vidrarias comuns em laboratório e equipamentos como balança analítica (Shimadzu, Modelo AY220), estufa de esterilização e secagem (Biopar, Modelo s150), agitador mecânico (Fisatom Equipamentos Científicos Ltda., Modelo 200.180) e medidor de ponto de fusão (Gehaka, Modelo PF $1500)$.

\section{Metodologia \\ Produção do filme}

Para a produção do biopolímero, foi preparada uma solução aquosa de farinha de arroz a $5 \%(\mathrm{~m} / \mathrm{m})$ comágua deionizada.Essa solução foi homogeneizada em agitador mecânico a $1.000 \mathrm{rpm}$ por $15 \mathrm{~min}$. Após a agitação, foi feito o ajuste de $\mathrm{pH}$ para 10 com a adição de 2 gotas de $\mathrm{NaOH}$ (anidra em escamas; Unipar; alcalinidade total $97,5 \% \mathrm{~m} / \mathrm{m}$ pelo método MAL-055) em solução $50 \%(\mathrm{~m} / \mathrm{v})$ juntamente com $10 \mathrm{~mL}$ de ácido cítrico aquoso $0,1 \mathrm{~mol} \cdot \mathrm{L}^{-1}$ e $0,3 \mathrm{~g}$ de glicerol puro bidestilado (Farmax) para cada grama de farinha de arroz utilizada. Após a adição de todos os reagentes, a solução foi aquecida em banho-maria até atingir $85^{\circ} \mathrm{C}$. Em seguida, a solução foi mantida em descanso até resfriar à temperatura ambiente $\left(25^{\circ} \mathrm{C}\right)$. Passado o tempo de resfriamento, os frutos foram imersos na solução por $30 \mathrm{~s}$ e reservados para a secagem do gel e a formação do filme.

\section{Perda de massa}

Pesou-se cada fruto no primeiro, sétimo, nono e décimo quarto dia. Nesse período, os frutos foram armazenados sobre a bancada do laboratório em temperatura ambiente. Registrou-se, por meio de imagens, cada fruto ao longo desse período, tornando possível o acompanhamento das propriedades organolépticas. Após 16 dias, os frutos foram repartidos, para que também houvesse análise organoléptica em sua parte interna.

\section{Acidez total titulável}

Os frutos selecionados foram inicialmente higienizados em água corrente, secos com papel-toalha e repartidos ao meio. Em um frasco Erlenmeyer, foi adicionado $1 \mathrm{~g}$ de polpa de tomate ou banana macerada, juntamente com $30 \mathrm{~mL}$ de água destilada e 2 gotas do indicador fenolftaleína 1\% alcoólica e titulou-se com uma solução aquosa de $\mathrm{NaOH}$ a $0,1 \mathrm{~mol} \cdot \mathrm{L}^{-1}$ até o ponto de equivalência. Todas as titulações foram realizadas em triplicata.

\section{Ponto de fusão}

Injetou-se a solução filmogênica com auxílio de uma seringa de $1 \mathrm{~mL}$ e agulha de $0,33 \mathrm{~mm}$ em uma das extremidades dos capilares lacrados. Após o preenchimento, os capilares foram levados à estufa por $4 \mathrm{~h}$ a $50{ }^{\circ} \mathrm{C}$, para a secagem da solução interna, e na sequência foram armazenados no dissecador a vácuo por $20 \mathrm{~h}$, após o que foram inseridos no aparelho medidor de ponto de fusão. As medições foram realizadas em triplicata. 


\section{RESULTADOS}

\section{Perda de massa}

Os resultados (Tabelas 1 e 2) mostram que a perda de massa é maior para a banana quando comparada com o tomate. Tal fato é explicado pela banana ser um alimento de fácil oxidação ${ }^{4}$. Outro fator considerável é a presença de ácido cítrico (ácido 2-hidroxi-1,2,3-propanotricarboxílico), um conservante alimentício natural, na composição do tomate. Entretanto, a banana com revestimento apresentou uma perda de massa inferior à banana sem revestimento, confirmando trabalhos anteriores ${ }^{4,5,6}$, que mencionam a ação do protetor biopolimérico como barreira para trocas gasosas e perda de vapor d'água, modificando a atmosfera e retardando o amadurecimento do fruto.

Em relação ao tomate sem e com revestimento, os resultados não foram significativos pelo fato dos valores de perda de massa (em gramas e percentual) serem próximos entre si.

Tabela 1: Resultados obtidos nas pesagens com (C) ou sem (S) revestimento por biopolímero.

\begin{tabular}{|c|c|c|c|c|}
\hline \multirow{2}{*}{} & \multicolumn{4}{|c|}{ Massa (g) } \\
\cline { 1 - 3 } & Dia 1 & Dia 7 & Dia 9 & Dia 14 \\
\hline Banana & 94,8332 & 84,2124 & 81,1489 & 73,5096 \\
\hline C & & & & \\
\hline Banana & 93,6096 & 80,3938 & 76,9656 & 68,0847 \\
\hline S & & & & \\
\hline Tomate & 88,8692 & 86,3103 & 85,6307 & 83,5204 \\
\hline C & & & & \\
\hline Tomate & 98,3594 & 95,1851 & 94,5401 & 92,2695 \\
\hline S & & &
\end{tabular}

Tabela 2: Perda de Massa com (C) ou sem (S) revestimento por biopolímero.

\begin{tabular}{|c|c|c|}
\hline & Perda total de massa $\mathbf{( g )}$ & Perda de massa (\%) \\
\hline Banana & 21,3236 & 22,5 \\
\hline $\mathbf{C}$ & 25,5249 & 27,3 \\
\hline $\begin{array}{c}\text { Banana } \\
\text { S }\end{array}$ & 5,3488 & 6,01 \\
\hline $\begin{array}{c}\text { Tomate } \\
\text { C }\end{array}$ & 6,0899 & \\
\hline Tomate & S & 6,19 \\
\hline
\end{tabular}

\section{Contaminação por microrganismos}

No $16^{\circ}$ dia, notou-se que a banana sem revestimento apresentava uma região com pontos na cor laranja (Fig. 1A), característicos do fungo Colletotrichum musae (Fig. 1B), comum nesse tipo de fruto. Apesar das duas bananas, com e sem revestimento, encontrarem-se no mesmo recipiente vítreo, a fruta revestida não apresentou contaminação do fungo. Dessa forma, concluise que o biopolímero impediu a proliferação de fungos na fruta analisada.

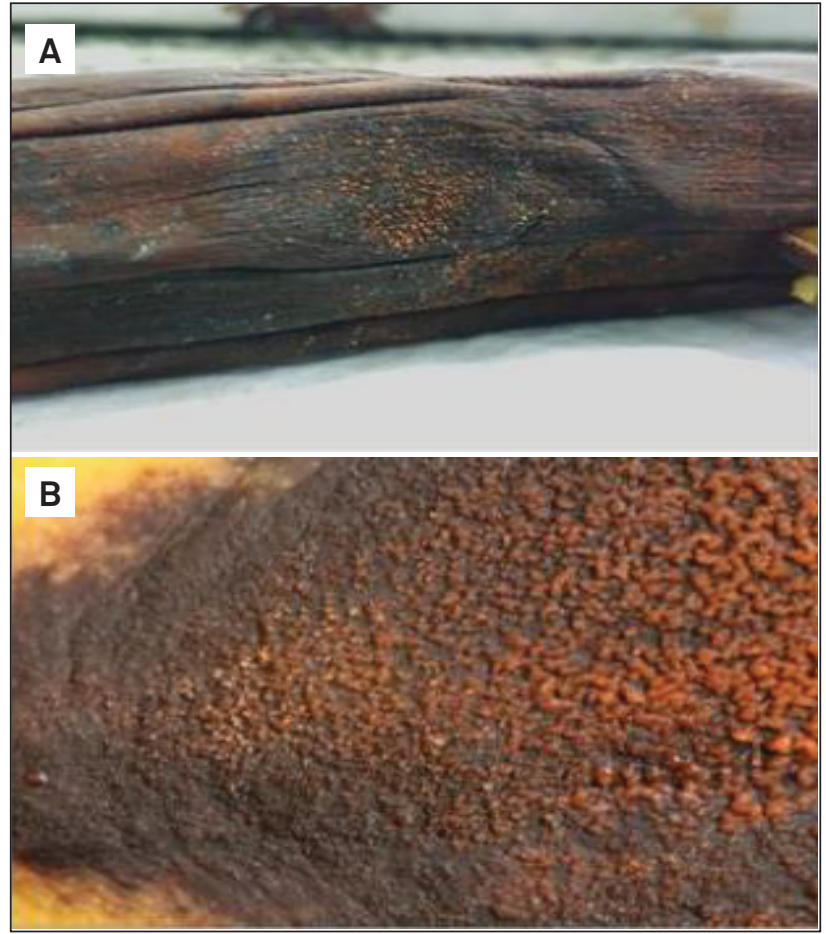

Figura 1: (A) Banana sem revestimento, após o 16ํㅡ dia de exposição ao ambiente, contaminada pelo fungo Colletotrichum musae. (B).

\section{Reações bioquímicas no amadurecimento dos frutos}

O amadurecimento é resultado de diversas reações que ocorrem principalmente na polpa dos frutos. A maturação e o escurecimento desses alimentos estão diretamente relacionados com a ação enzimática e a oxidação de determinadas substâncias² ${ }^{2}$.

\section{Análise da banana}

Para verificar a maturação da banana, utilizou-se uma banana revestida com o biopolímero e outra isenta de revestimento. As bananas foram expostas ao ambiente por um período de 16 dias (Fig. 2). Durante o período de maturação, observou-se o escurecimento da casca da banana, resultado da ação de enzimas que oxidam os fenóis, dando origem a compostos denominados melaninas. A produção de etileno $\left(\mathrm{C}_{2} \mathrm{H}_{4}\right)$, que ocorre no interior da polpa da fruta, também é responsável pela sua pigmentação e amadurecimento $^{7}$. Ao longo de 16 dias, foi possível observar que o número de regiões da cor amarela é maior na fruta revestida com o biopolímero. Dessa forma, pode-se dizer que o biopolímero age

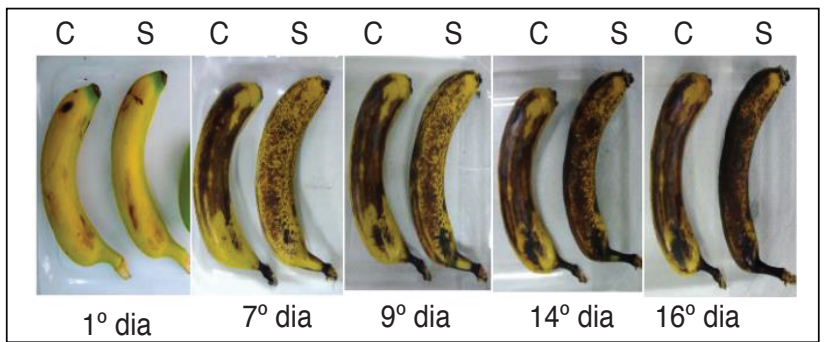

Figura 2: Processo de maturação da banana com (C) e sem (S) Revestimento. 
como um filme de proteção inibindo fatores que causam a rápida maturação da banana.

\section{Análise do tomate}

O tomate adquire as colorações verde, amarelo e vermelho, devido à presença de clorofila a e b, caroteno e licopeno, respectivamente, sendo que a clorofila é oxidada pelo etileno para formação do caroteno ${ }^{8}$. De acordo com a Fig. 3, observa-se a permanência da cor verde no tomate revestido com biopolímero, resultante da diminuição das trocas gasosas (respiração) entre o fruto e o meio atmosférico, sendo que a disponibilidade de oxigênio é essencial para a ação do etileno. Nota-se que houve redução na degradação da clorofila nos frutos com revestimento.

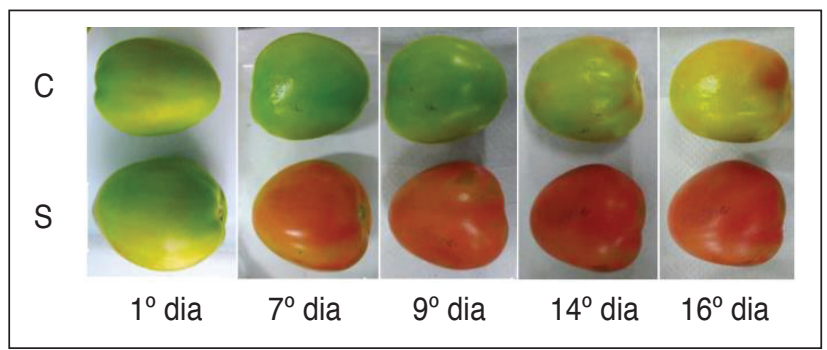

Figura 3: Processo de maturação do tomate com (C) e sem (S) revestimento.

\section{Análise da polpa}

Ao final do $16^{\circ}$ dia, os tomates (Fig. 4) e as bananas (Fig. 5) foram cortados ao meio para que o aspecto de suas polpas fosse analisado. Observou-se que houve conservação da parte externa e interna dos frutos com revestimento. $\mathrm{O}$ tomate sem revestimento (Fig. 4B) encontrava-se desejável para o consumo humano, enquanto o fruto com revestimento (Fig. 4A) ainda apresentava grande quantidade de clorofila, justificando a predominância da cor verde.

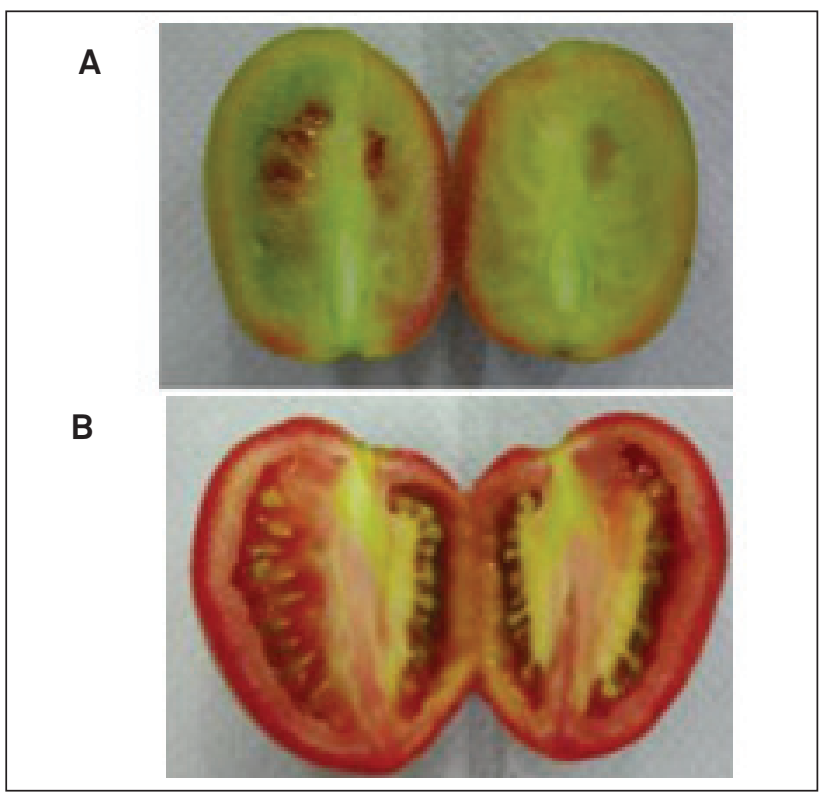

Figura 4: Tomate com (A) e sem (B) biopolímero.
A banana sem revestimento (Fig. 5B) apresentou aspectos de putrefação e sua polpa revelava uma coloração escura, resultado da ação das enzimas peroxidase e polifenoloxidase ${ }^{7}$. A fruta com revestimento (Fig. 5A) apresentou coloração amarelada com algumas regiões escuras, indicando um menor grau de maturação, sendo que a banana com proteção polimérica também demonstrou maior rigidez.

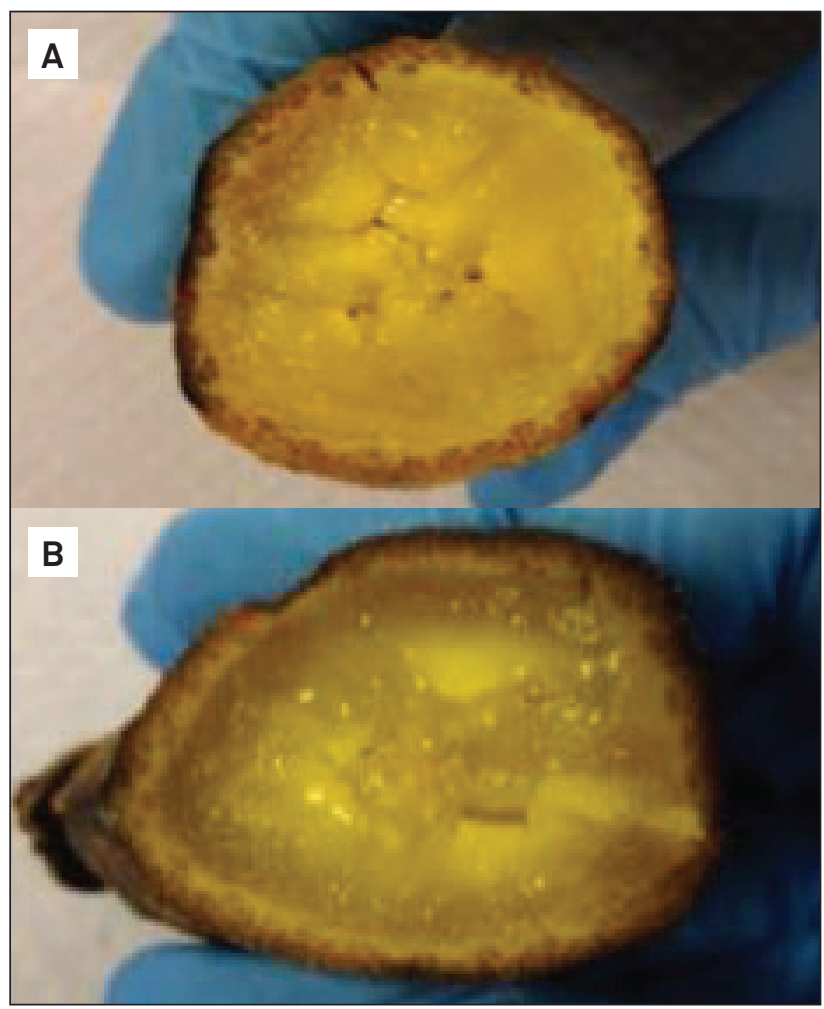

Figura 5: Banana com (A) e (B) sem biopolímero.

\section{Acidez total titulável}

A análise da acidez total titulável (ATT) das amostras de tomate em seu $10^{\circ}$ dia de teste evidenciou um decréscimo na acidez de $71,0 \%$ (41,3 mg) na amostra com revestimento e 55,6\% (32,3 mg) na amostra sem revestimento, quando comparadas à amostra modelo inicial, em que a ATT encontrava-se em 58,1 mg/100 g (Tabela 3). Desse modo, percebe-se o consumo de ácidos orgânicos no processo metabólico dos frutos e a consequente maturação com aumento da qualidade do fruto para consumo. Segundo Rocha e colaboradores ${ }^{9}$, o consumo de ácidos orgânicos é o principal responsável pela redução da acidez.

Em relação às amostras de banana analisadas no $8^{\circ}$ dia de teste observa-se, de forma inversa aos tomates, o aumento da acidez, de 52,5\% (10,5 mg) na amostra com revestimento e de 32,6\% (6,5 mg) na amostra sem revestimento, quando comparadas com a amostra inicial, cuja ATT correspondente era de 19,90 mg/100 g. Dados obtidos por Lichtemberg ${ }^{7}$ mencionam que a acidez da banana normalmente aumenta até atingir um valor máximo, quando a casca está totalmente amarela, para depois decrescer, predominando o ácido málico. Convém ressaltar que a banana, durante seu amadurecimento, 
produz substâncias voláteis, tais como ésteres, álcoois, aldeídos, cetonas, aminas e fenóis, que são importantes para o seu odor característico ${ }^{10}$. Portanto, é possível inferir que o biopolímero atua como barreira física, dificultando a volatilização do ácido málico e as substâncias voláteis produzidas pelo fruto durante seu amadurecimento, ocasionando aumento de acidez ao longo de 8 dias.

Tabela 3: Resultados finais referentes à análise de acidez total titulável aplicada no tomate.

\begin{tabular}{|c|c|c|}
\hline Amostras & $\begin{array}{c}\text { Média } \\
(\mathbf{m g} / \mathbf{1 0 0} \mathbf{~ g})\end{array}$ & $\begin{array}{c}\text { Desvio padrão } \\
(\mathbf{m g})\end{array}$ \\
\hline $\begin{array}{c}\text { Sem biopolímero } \\
\text { 10 dia }\end{array}$ & 58,1 & $\pm 12,1$ \\
\hline $\begin{array}{c}\text { Sem biopolímero } \\
10^{\circ} \text { dia }\end{array}$ & 25,8 & $\pm 8,1$ \\
\hline $\begin{array}{c}\text { Com biopolímero } \\
10^{\circ} \text { dia }\end{array}$ & 16,8 & $\pm 3,8$ \\
\hline
\end{tabular}

Tabela 4: Resultados finais referentes à análise de acidez total titulável aplicada na banana.

\begin{tabular}{|c|c|c|}
\hline Amostras & $\begin{array}{c}\text { Média } \\
(\mathrm{mg} / 100 \mathrm{~g})\end{array}$ & $\begin{array}{c}\text { Desvio padrão } \\
\text { (mg) }\end{array}$ \\
\hline $\begin{array}{c}\text { Sem biopolímero } \\
1^{\circ} \mathrm{dia}\end{array}$ & 19,9 & $\pm 4,1$ \\
\hline $\begin{array}{c}\text { Sem biopolímero } \\
8^{\circ} \text { dia }\end{array}$ & 26,4 & $\pm 6,9$ \\
\hline $\begin{array}{c}\text { Com biopolímero } \\
8^{\circ} \mathrm{dia}\end{array}$ & 30,4 & $\pm 4,1$ \\
\hline
\end{tabular}

\section{Ponto de fusão}

Os filmes apresentaram ponto de fusão médio na faixa de 105 ${ }^{\circ} \mathrm{C}$, semelhante ao polietileno de baixa densidade apresentado por Coutinho e seus colaboradores ${ }^{11}$. Apesar de ter um valor de temperatura de fusão baixo, quando comparado à maioria dos plásticos comerciais disponíveis no mercado $\left(>180^{\circ} \mathrm{C}\right.$ ), o biopolímero elaborado satisfaz as condições esperadas, visto que será destinado ao revestimento de frutos e leguminosas no estágio de pós-colheita, durante armazenamento e transporte, e, nessas condições, as temperaturas raramente são superiores a $30^{\circ} \mathrm{C}$.

\section{CONCLUSÃO}

Tendo em vista as análises realizadas, pode-se confirmar a eficácia do biopolímero desenvolvido a partir da farinha de arroz como película protetora dos frutos utilizados neste estudo. Em 14 dias, a perda de massa da banana (Musa spp.) revestida com o biopolímero foi inferior à da banana sem cobertura filmogênica. Entretanto, os tomates (Lycopersicon esculentum) com e sem revestimentos apresentaram valores semelhantes no teste. Nas figuras apresentadas, é possível observar a desaceleração no processo de maturação dos frutos, de maneira que a respiração e a transpiração foram dificultadas e a ação enzimática foi retardada. A contaminação pelo fungo Colletotrichum musae e os fungos filamentosos (bolor), foi observada somente na superfície da banana isenta de revestimento, mostrando a ação do material polimérico contra a proliferação de fungos nesses frutos.

Os resultados de ATT mostraram que a acidez do tomate recoberto diminuiu ao longo de 10 dias, mantendo sua qualidade de consumo. A acidez da banana aumentou devido à retenção de substâncias voláteis produzidas durante seu amadurecimento. Considerando que o ponto de fusão do biopolímero é de aproximadamente $105^{\circ} \mathrm{C}$, fica evidente que a utilização desse material como revestimento é adequado para o estágio de póscolheita, armazenamento e transporte dos frutos em questão.

O agricultor pode fabricar o biopolímero e aplicá-lo por borrifamento, por exemplo. O prolongamento da vida do alimento favorece a exportação, permitindo que o produto chegue a outros continentes.

\section{REFERÊNCIAS}

1. Food and Agriculture Organization of the United Nations. Global Food Losses and Food Waste. 2011. Study conducted for the International Congress Save Food, Düsseldorf. [Acesso 27 set 2017] Disponível em: http://www.fao.org/fileadmin/user_upload/ suistainability/pdf/Global_Food_Losses_and_Food_Waste.pdf

2. Chitarra MIF, Chitarra AB. Pós-colheita de frutas e hortaliças: fisiologia e manuseio. 2 ed. Lavras: Universidade Federal de Lavras; 2005.

3. Dias AB. Desenvolvimento e caracterização de filmes biodegradáveis obtidos de amido e de farinha de arroz. Florianópolis. Dissertação [Mestrado em Engenharia de Alimentos] - Faculdade de Engenharia de Alimentos, Universidade Federal de Santa Catarina; 2008.

4. Pereira GA, Santaella MB, Santana LM, Alves M, Silva EC. Desinfestação in vitro da Bananeira 'Farta Velhaco (Sub Grupo AAB)' Ativo. Revista Caatinga. 2015(28)4:64-69. https://doi. org/10.1590/1983-21252015v28n407rc

5. Oliveira MA. Utilização de película de fécula de mandioca como alternativa à cera na conservação pós-colheita de frutos de Goiaba (Psidium guajava). Piracicaba. Dissertação [Mestrado] - Escola Superior de Agricultura "Luiz de Queiroz", Universidade de São Paulo; 1996.

6. Cereda MP, Bertolini AC, Evangelista RM. Uso do amido em substituição às ceras na elaboração de "películas" na conservação pós-colheita de frutas e hortaliças: estabelecimento de curvas de secagem. Congresso Brasileiro de Mandioca. Recife; 1992.

7. Lichtemberg LA. Colheita e pós-colheita da banana. Informe Agropecuário. 1999;20(196):73-90.

8. Luiz KMB. Avaliação das características físico-químicas e sensoriais de tomates (lycopersicum esculentum mill) armazenados em refrigeradores domésticos. Florianópolis. Dissertação [Mestrado em Engenharia de Alimentos] - Faculdade de Engenharia de Alimentos, Universidade Federal de Santa Catarina, Florianópolis; 2005.

9. Rocha RHC, Menezes JB, Morais EA, Silva GG, Ambrósio MMQ, Alvez MZ. Uso do índice de degradação do amido na determinação da maturidade da manga Tommy Atkins. Rev Bras Frutic. 2001;23(2):302305. https://doi.org/10.1590/S0100-29452001000200020

10. MORTON, I. D.; MACLEOD, A. J. Food Flavours. 1 ed. Amsterdam: Elsevier Science Publishers, 1990.

11. Coutinho FMB, Mello IL, Maria LCS. Polietileno: principais tipos, propriedades e aplicações. Polímeros 2003;(13)1:1-13. https:// doi.org/10.1590/S0104-14282003000100005 